\title{
Localized scleroderma
}

INSERM

\section{Source}

INSERM. (1999). Orphanet: an online rare disease and orphan drug data base. Localized scleroderma. ORPHA:90289

Localized scleroderma is the skin localized form of scleroderma (see this term) characterized by fibrosis of the skin causing cutaneous plaques or strips. 